\title{
"Em nome da natureza": discursos e mobilizações católicas no Brasil contra a inserção de discussões em torno do gênero na escola
}

"In the name of nature": catholic speeches and mobilizations in Brazil against inserting discussions in the gender tone of school

Emanuel Freitas da Silva ${ }^{1}$

\section{Resumo}

Inúmeras discussões em torno das questões que envolvem a temática "gênero e sexualidade" têm sido travadas nos últimos anos, em especial no que tange à elaboração de políticas públicas que visem combater o histórico processo de exclusão de sujeitos que divergem do padrão hegemônico estabelecido para o uso dos corpos. Nesse sentido, a própria utilização do termo "gênero", semantizado como um novo aporte "ideológico", tem sido combatida numa poderosa campanha engendrada por lideranças religiosas (católicas e protestantes), no Brasil e no mundo, para a retirada do termo de documentos públicos e políticas públicas, em especial daquelas ligadas à educação. O objetivo desse texto é apresentar os principais argumentos de lideranças católicas, em especial ligadas ao movimento de Renovação Carismática, em textos elaborados para o "esclarecimentos de fiéis" acerca dos "perigos da ideologia de gênero" (destacando três autores católicos) e a mobilização feita, no Brasil, pela CNBB e por algumas dioceses do país.

Palavras-chave: Sexualidade; Mobilização; Disputas politicas.

\begin{abstract}
Numerous discussions on the issues surrounding the theme of "gender and sexuality" have been fought in recent years, especially with regard to the elaboration of public policies aimed at combating the historical process of exclusion of subjects that diverge from the established hegemonic standard for the use of bodies. In this sense, the very use of the term "gender", semantized as a new "ideological" contribution, has been combated in a powerful campaign engendered by religious leaders (Catholic and Protestant) in Brazil and in the world for the withdrawal of documents and public policies, especially those related to education. The purpose of this text is to present the main arguments of

\footnotetext{
${ }^{1}$ Doutor em Sociologia (UFC), mestre (UFRN) e bacharel (UECE) em Ciências Sociais, licenciando em História (UECE), professor assistente de Teoria Política (UECE/FACEDI). Contato: emanuel.freitas@uece.br
} 
Religare, ISSN: 19826605, v.15, n.2, dezembro de 2018, p.505-525.

Catholic leaders, especially those related to the Charismatic Renewal movement, in texts elaborated for the "clarification of the faithful" about the "dangers of gender ideology" (highlighting three Catholic authors) made in Brazil by the CNBB and some dioceses of the country.

Keywords: Sexuality; Mobilization; Political disputes.

\section{Introdução}

Em 17 de agosto de 2015, o Ministério da Educação emitia a "Nota Técnica" de número 24, assinada conjuntamente pela Secretaria de Educação Continuada, Coordenação Geral de Direitos Humanos e pela Diretoria de Políticas em Educação, Direitos Humanos e Cidadania, em que buscava reiterar “a importância dos conceitos de gênero e orientação sexual para as políticas educacionais e para o próprio processo pedagógico" (p. 19). A razão da Nota devia-se ao fato de, mesmo após todo o processo de elaboração do Plano Nacional de Educação (PNE), dos Planos Estaduais de Educação (PEE) e dos Planos Municipais de Educação (PME), fruto de intensos debates com diversos setores da sociedade civil que, acolhendo as demandas por direitos e reconhecimentos identitários, em especial com relação às questões de gênero em sua dimensão mais ampla (machismo, violência contra a mulher, espaço da mulher na esfera pública, discriminação contra a população LGBT, violência contra esta etc), o momento da votação dos planos nas devidas casas legislativas (Congresso Nacional, Assembleias Estaduais e Câmaras Municipais), estava sendo conduzida por meio de debates os mis obscuros e desinformadores possíveis.

Iniciara-se em 2015² uma verdadeira "cruzada" com a qual os idealizadores das propostas de educação não contavam: a mobilização contra as

\footnotetext{
2 Na verdade, um ensaio exitoso dessa "cruzada" havia sido realizado em 2011 quando, por pressão da chamada "bancada religiosa" no Congresso Nacional, a então presidente Dilma Rousseff (PT) ordenou o recolhimento de um kit anti-homofobia que havia sido produzido pelo MEC, na gestão de Fernando Haddad, e que seria distribuído nas escolas de ensino médio para se discutir problemas em torno da discriminação contra gays, lésbicas, travestis e transexuais no ambiente escolar. Alcunhado de "kit gay", o material serviu como moeda de troca e pressão
} 
Religare, ISSN: 19826605, v.15, n.2, dezembro de 2018, p.505-525.

propostas, em especial àquelas que diziam respeito ao tratamento das questões de gênero ${ }^{3}$ na escola, da forma mais deturpada possível, utilizando-se, dentre outras coisas, de um termo que se consolidaria na imprensa e na política: “ideologia de gênero". Mobilizados pelo combate à essa "ideologia", parlamentares de diversos partidos e ligados à diversas denominações religiosas juntaram-se, numa verdadeira "cruzada" pelo país, para retirar dos diversos planos qualquer menção à palavra "gênero" e outras que lhe dissessem respeito.

O motivo da mobilização seria que a suposta "ideologia de gênero" seria uma "imposição que destruiria a família tradicional" (composta unicamente na forma de um pai, uma mãe e sua prole) e de que não seria papel da escola educar as crianças quanto às questões sexuais e morais, mas sim da família ${ }^{4}$.

O MEC lamentava, assim, que a retirada desses termos significaria a reprodução de uma ignorância acerca da "dimensão histórica, política, cultural e social das diferenças e do próprio processo de construção subjetiva de homens e mulheres". Até o momento da produção da Nota, oito Estados ${ }^{5}$ já haviam votado seus planos estaduais e haviam retirado as menções sugeridas pelo Ministério: Acre, Tocantins, Paraíba, Pernambuco, Espírito Santo, Paraná, Rio Grande do Sul e o Distrito Federal. Até ali, apenas Maranhão, Amapá, Mato Grosso e Mato Grosso do Sul haviam votado e mantido às referências às questões de gênero em seus planos.

Este artigo tem como objetivo apresentar os principais argumentos dos opositores da presença das questões de gênero na escola, com destaque para

contra o recém iniciado governo Dilma, tendo representado uma considerável derrota ao movimento organizado e, portanto, ao combate às discriminações.

${ }^{3} \mathrm{Na}$ proposta do MEC, contudo, a referência era o "combate à discriminação racial, de orientação sexual ou de identidade de gênero", uma perspectiva, portanto, bastante plural.

${ }^{4}$ No encalço desse discurso, dois projetos "moralizadores" direcionados à questão da educação foram gestados e, a par de seu claro conteúdo doutrinador e ideológico, são transmitidos e definidos como "neutros": o "Escola sem Partido", que visa coibir qualquer manifestação ideológica por parte da escola que contrarie os "valores da família"; e o "Estatuto da Família" que, além definir família unicamente como "a união de um homem e uma mulher", ainda prevê, na escola, o ensino de "educação para a família".

${ }_{5}^{5}$ Sobre isso, ver: http://www1.folha.uol.com.br/educacao/2015/06/1647528-por-pressao-planosde-educacao-de-8-estados-excluem-ideologia-de-genero.shtml. Acesso em 10/09/2017. 
Religare, ISSN: 19826605, v.15, n.2, dezembro de 2018, p.505-525.

pronunciamentos da Conferência Nacional dos Bispos do Brasil (CNBB) e de mobilizações produzidas por comunidades ligadas à Renovação Carismática Católica (RCC), através de suas lideranças. Antes disso, porém, apresentarei algumas questões contextuais acerca das "contaminações" entre religião e política no Brasil, assim como uma intentada compreensão do que estes atores do campo político-religioso compreendem como "ideologia de gênero". Assim sendo, o leitor já está cônscio de que minha análise não compreenderá, por decidido arbítrio, as mobilizações originadas no campo religioso evangélico, também bastante considerável.

\section{A política "capturada" pela religião? Um esboço do Brasil contemporâneo}

A disputa presidencial de 2014, sem dúvida alguma a mais concorrida ${ }^{6}$ desde a redemocratização brasileira ocorrida no final dos anos 80, reposicionou atores sociais, até então esquivados do jogo político, dentro da disputa em curso, exigindo destes tomadas de posição mais precisas com relação aos rumos do processo eleitoral. Dentre estes, podemos destacar atores do campo religioso que, desde os anos 80, têm tomado parte nos diversos processos eleitorais.

Contudo, se têm sido recorrentes empreitadas políticas de lideranças religiosas cristãs do segmento evangélico ${ }^{7}$ ou mesmo da ala mais progressista da Igreja Católica - como é o caso das Comunidades Eclesiais de Base (CEB's) ${ }^{8}$-, não se observavam tomadas de posições mais claras no jogo político por parte de

\footnotetext{
${ }^{6}$ Disputaram tal eleição: Dilma Rousseff (PT, candidata à reeleição), Aécio Neves (PSDB), Marina Silva (PSB, que substituiu Eduardo Campos, morto em acidente aéreo), Pastor Everaldo (PSC), Luciana Genro (PSOL), Levy Fidelix (PRTB), Eduardo Jorge (PV), Zé Maria (PSTU), José Eymael (PSDC) e Mauro Iasi (PCB) e Rui Costa (PCO). Dilma e Aécio receberam no primeiro turno, respectivamente, 42 e $33 \%$ dos votos válidos, saindo-se a petista vencedora no segundo turno com uma ligeira margem de vantagem: $52 \%$ dos votos válidos, contra $48 \%$ de votos conferidos a seu opositor, margem de vitória bastante diminuta em relação aos pleitos presidenciais anteriores. (Dados do TSE).

7 Com atuação política, inclusive parlamentar, desde a Assembleia Nacional Constituinte, de 1988.

${ }^{8}$ Sobre isso, ver MAINWARING (1989).
} 
Religare, ISSN: 19826605, v.15, n.2, dezembro de 2018, p.505-525.

lideranças da Renovação Carismática Católica (RCC), como se pôde observar a partir das eleições de $2010^{9}$, e ainda mais nas eleições de 2014, no que tange ao voto presidencial, sendo a RCC o segmento católico com maior crescimento de engajamento das disputas eleitorais dos anos 2010. Isso porque, desde 2010, vimos "uma reposição dos temas na agenda política da maioria dos grupos religiosos favorecendo as questões de cunho moral e privado" (MACHADO, 2015, p. 34) ${ }^{10}$, o que fortalecera a já consolidada atuação de políticos ligados às denominações evangélicas e, agora, favorecia a empreitada de políticos ligados à RCC. Assim sendo, a atuação deliberada de atores do campo religioso (evangélicos e carismáticos) na política eleitoral nos permite compreender o ativismo religioso conservador que, caucionado numa visão negativa da política brasileira, vai mobilizando-se na perspectiva de construção de uma nova cultura política no país, crente no "dever moral" de interferir nos rumos das disputas eleitorais e, como veremos aqui, na condução das políticas públicas. Vejamos algumas chaves de compreensão das relações entre religião e política no Brasil contemporâneo.

Cecília Mariz (2006) compreende as inserções da Renovação Carismática Católica na política, por exemplo, pensando nas relações que o movimento estabelece com os dilemas dentro do catolicismo com as "cosmovisões modernas" da vida social, pondo-se em diálogo, por vezes conflitivo, com as estruturas e grupos do mundo secular, exercitando uma "barganha cognitiva" engendrada por uma reflexividade a partir do embate com os valores "do mundo", cada vez menos capturados ou formatados pela teologia cristã ${ }^{11}$.

\footnotetext{
9 Particularmente na militância em torno da questão do "aborto" e dos direitos das minorias. Sobre isso, ver MACHADO (2012) que, apesar de tratar da atuação de evangélicos, tal atuação se assemelha em muitos aspectos à atuação de lideranças e parlamentares católicos, sobretudo os ligados à RCC.

${ }^{10}$ Embora estudos como os de MIRANDA (1999) e MACHADO (2006) tenham observado tal empreitada da RCC já nos anos 90, sustento aqui que a mudança, nos anos 2010, operou-se em relação a uma militância mais perceptível no que tange à disputa presidencial, e não nas disputas legislativas, como os estudos já apontavam.

${ }^{11}$ Em seu estudo sobre a ética das grandes religiões mundiais, Weber (2012) destacou o confronto instaurado pelas "religiões de salvação", no que tange ao tensionamento de seus fiéis com a realidade material, que se destitui de qualquer valor ou significado frente à realidade espiritual
} 
Religare, ISSN: 19826605, v.15, n.2, dezembro de 2018, p.505-525.

Joanildo Burity (2015), ao tratar das dimensões da religião na cena pública, elenca como uma chave de compreensão para as atuais modalidades de tal "encenação" as noções de "agência" e "antagonismo". Para o autor, a atual mobilização política de grupos religiosos em torno de agendas públicas que, de uma forma ou de outra, lhe dizem respeito, pode ser compreendida como uma "agenda reativa" às inúmeras mudanças no plano sociocultural, "rápidas" por demais e que, por isso mesmo, ameaçam "profundamente valores e práticas tradicionais, provocando assim uma tentativa de reasserção de vozes religiosas" num mundo cada vez mais tendente à secularização, tendo, pois, uma "conotação conservadora", pois busca interromper ou reverter mudanças que tragam prejuízos à pregação religiosa; ou como uma "agenda construtiva", por meio da qual os grupos religiosos buscariam refazer suas posições para responder aos desafios contemporâneos que lhes são impostos pela sociedade; isso seria um viés mais progressista dos grupos. Concordando com o autor, observo a mobilização contra a "ideologia de gênero" como a faceta "reativa" dos grupos religiosos evangélicos e católicos carismáticos, assim como o "Escola sem partido" e o "Estatuto da família" como sua faceta "construtiva" no atual cenário de engajamento dos atores religiosos no campo político.

Maria das Dores Machado (2015), por sua vez, ao estudar a participação de lideranças da Renovação Carismática Católica na política brasileira, destaca que, apesar de já se verificarem interesses pelos processos eleitorais desde os anos 1990, os últimos anos têm apresentado um importante aumento desse segmento nas Casas Legislativas, engendrando, junto com políticos advindos das Igrejas Pentecostais, "uma posição de ativismo político com o propósito de restaurar ou criar uma nova cultura política no país", postando-se, tais políticos, como "farol ético da sociedade brasileira" (MACHADO, 2015, p. 48).

apregoada por estas, uma vez que toda a existência material é explicada a partir dos valores éticos assumidos por tais religiões. 
Religare, ISSN: 19826605, v.15, n.2, dezembro de 2018, p.505-525.

Isso porque tais lideranças creem-se como arautos de um "dever moral de participar da política e de mudá-la", em especial com o avanço de pautas identificadas com os Direitos Humanos ou com pautas de minorias, representadas por tais segmentos como "trevas" a serem combatidos pela participação política, encarada nos termos de uma "batalha espiritual":

[...] atentos aos movimentos culturais que questionam a ordem de gênero e a moralidade sexual cristã e percebendo a importância crescente da normatividade legal e do ideário dos direitos humanos na sociedade contemporânea, pentecostais e carismáticos se esforçam para readequar seus discursos e sus formas de atuação na sociedade mais ampla [...] associação da evangelização a uma forma de batalha, na qual os que não seguem o cristianismo devem ser combatidos. Ou seja, o discurso predominante tanto entre carismáticos como entre pentecostais parece advir da teologia da guerra ao mal que, em diferentes momentos da história ocidental, gerou perseguições às minorias culturais (MACHADO, 2015, p. 65-66)

Magali Cunha (2017) apresenta arguta análise acerca das novas dimensões do que nomeia como "neoconservadorismo evangélico" que auxilia na compreensão das tomadas de posição de atores do campo religioso em relação às questões de gênero. A bandeira maior desse novo conservadorismo, que possui uma considerável atuação nas mídias digitais, seria a "salvação da família", em especial contra o que consideram ser uma "ditadura gayzista" que busca "impor o seu estilo de vida" ao conjunto da população; e, assim, essa bandeira torna-se uma "única" a congregar católicos e evangélicos na luta "contra a ideologia de gênero". Tal congregação de interesses é ilustrado pela autora através da similitude de argumentos postos tanto pelo Pastor Silas Malafaia, da Igreja Assembleia de Deus, quanto pelo Padre Paulo Ricardo, importante pregador da Renovação Carismática Católica, ambos liderando “cruzadas" pela retirada do termo "gênero" e seus semelhantes dos planos de educação.

Apresentadas estas noções acerca das relações entre religião e política no cenário contemporâneo, penso ser agora o momento de discutir os elementos discursivos da mobilização "contra a ideologia de gênero", por parte de atores 
Religare, ISSN: 19826605, v.15, n.2, dezembro de 2018, p.505-525.

do campo religioso católico, oferecendo, antes, uma compreensão de como e por quê as questões de gênero são tratadas como "ideologia" no campo religioso, em geral, e no católico, em particular.

\section{Acerca da ideologia que faz o gênero, do gênero que faz a ideologia: elementos ideológicos em torno do termo "ideologia de gênero"}

A desvinculação historicamente legitimada entre sexo/gênero, problematizada pelos diversos estudos nas áreas de Humanidades (Sociologia, Antropologia, Filosofia, História, Psicologia dentre outras) configura-se como o principal elemento daqueles que militam pela igualdade de gênero e pela despatologização das identidades de gênero que fogem aos padrões construídos como moldes normalizadores; bem como constituiu-se como o principal elemento de ataque daqueles que enxergam nisso uma elemento "ideológico".

Em linhas gerais, podemos dizer que os estudos de gênero desenvolveram-se a partir dos anos 1970, e desde lá vêm definindo o gênero como uma construção social de atributos impostos diferenciadamente a homens e mulheres tomando como pressuposto diferenças sociais assentadas nas diferenças dos corpos, inscrevendo assim as diferenças na "ordem das coisas". Assim, a utilização do termo "gênero", e não do seu correlato "sexo", visa sublinhar as diferenciações fundadas a partir dos corpos, gerando um código de conduta e de lugar no mundo que, ideologicamente, seria a mais fiel representação das coisas, sua mais absoluta "naturalidade". O gênero, pois, seria a forma como as diversas culturas "organizam e interpretam a diferença sexual entre homens e mulheres" (YANNOULAS, 2001, p. 72).

Para Berenice Bento, importante pesquisadora de gênero no Brasil, os estudos da área, que avançaram desde as primeiras concepções do movimento feminista, hoje permitem:

Colocar as questões: como o gênero funciona nas relações sociais? De que maneira o gênero dá sentido à organização e à percepção do conhecimento histórico? Quais as representações simbólicas em torno das diferenças percebidas entre os sexos? 
Religare, ISSN: 19826605, v.15, n.2, dezembro de 2018, p.505-525.

Como e por que estas diferenças contribuem para criação e manutenção de poderes? Tudo isso implica ter um modelo analítico claro, que funcione de certa forma como uma bússola, na nebulosa e emaranhada rede das relações de gênero (BENTO, 2015, p. 78).

Nomes como Michel Foucault, Juditn Butler, Nancy Fraser, Raewyn Connl, Luce Irigaray (não por acaso, mulheres ou homossexuais) são, por um lado, considerados como ícones da conscientização da opressão historicamente assentada nas estruturas sociais; por outro, como personagens de uma desconstrução da "família tradicional" que devem ser denunciados e combatidos $^{12}$.

Justamente na substituição, na agenda política, do termo "sexo" por "gênero", ou por "discriminação de gênero", é que os opositores dos estudos de gênero, em sua maioria religiosos, vêm uma "ideologia". Ou seja, no momento de politização da categoria "gênero", tais atores enxergam a composição de uma “ideologia". Vejamos, a seguir, a fundamentação de três escritores católicos quanto ao que nomeiam como "ideologia de gênero".

Padre Olivier Bonnewijn, sacerdote belga e membro da Comunidade Católica Emanuel, da França, professor de ética em um seminário diocesano, assim expressa-se acerca da "ideologia de gênero":

A teoria de gênero e a terminologia que dela deriva têm suscitado vivos e importantes debates na sociedade atual, sobretudo porque começam a perder espaço em alguns países, onde já foram implementados como parte de um programa de educação, e, por outro lado, há projetos em outros países que caminham no sentido de implementá-las. Contudo, parece ainda haver uma espécie de blindagem acadêmica quanto ao debate da questão. Qualquer pesquisa que vá no sentido de fomentar as questões de gênero tem as portas abertas para seu financiamento e aprovação. Certamente, isso se atribui à necessária reflexão sobre o papel da mulher e seus direitos na sociedade contemporânea.

${ }^{12}$ Após ter sua mais conhecida frase ("ninguém nasce mulher, torna-se mulher") na prova do Exame Nacional do Ensino Médio (ENEM), em 2015, a filósofa francesa Simone de Beauvoir recebeu moção de repúdio da Câmara Municipal de campinas, depois de uma longa sessão onde proferiu-se inúmeros ataques à sua pessoa. Sobre isso, ver: https://brasil.elpais.com/brasil/2015/11/09/opinion/1447075142_888033.html 
Religare, ISSN: 19826605, v.15, n.2, dezembro de 2018, p.505-525.

No entanto, um franco debate deveria ser aberto justamente sobre a relação que existe entre a reflexão sobre a mulher na sociedade contemporânea e a adequação antropológica das teorias que fomentam tal reflexão, ou que dela decorrem, e que são depois traduzidas em propostas políticas e também econômicas, nacionais e internacionais. A partir de uma ressignificação da abordagem do relacionamento homem-mulher, está em jogo toda a concepção de ser humano que se pretende defender ou desconstruir (BONNEWIJN, 2015, p 8-9, grifo nosso).

O primeiro elemento a se destacar é que o sacerdote entende os estudos de gênero, antes de tudo, como uma "teoria", localizando-a como algo produzido no interior da Universidade (o que o levará a lamentar a disponibilidade considerável de financiamentos à pesquisas que tenham "gênero" como temática", assim como à quantidade de países que, a partir de tais pesquisas, estariam no caminho de implementar a sua "agenda"). Apesar de reconhecer que tais estudam contribuem com uma reflexão antropológica acerca da posição da mulher na sociedade, o sacerdote vê na ressignificação operacionalizada por tais estudos uma ameaça a "toda concepção de ser humano" estruturada até aqui.

Contudo, o que o sacerdote não consegue compreender é que, de fato, os estudos de gênero, ao lançarem luz sobre a forma como, historicamente, as relações entre os humanos foram estruturadas como relações entre os "sexos", ancorando uma série de desigualdades, tais estudos visam, exatamente, desconstruir tais desigualdade alicerçadas em supostas diferenças sexuais convertidas em diferenças sociais, por nós internalizadas, nos processos de socialização aos quais somos submetidos ao longo da vida, como categorias através das quais a sociedade estrutura-se para nós, em nós e nos estrutura a nós mesmos, engendrando concepções que inscrevem-se como provenientes da “própria natureza" (cf. BENTO, 2013, p.52). A incompreensão desse fato faz com que o sacerdote chegue a dizer que tais estudos pretendem "abolir qualquer ética 
Religare, ISSN: 19826605, v.15, n.2, dezembro de 2018, p.505-525.

em matéria sexual" (BONNEWIJN, 2015, p. 13), o que demonstra o desconhecimento, a fundo, de tais estudos ${ }^{13}$.

O sacerdote, salientando que os teóricos do gênero não são "pensadores de gabinete", mas "militantes que querem transformar o mundo", afirma que para estes "o sexo humano é insignificante"14, que buscam a "supressão pura e simples da família biológica" (outra imprecisão), que promovem "pornografia, prostituição e práticas sadomasoquistas" e "descontroem a família e a maternidade". Ora, é na ampliação da noção de família que se assenta a luta dos movimentos de minorias LGBT, o que não significa lutar pela sua supressão. Ademais, a representação da questão do gênero como "permissividade" dos comportamentos é, como veremos, o principal meio de descredenciamento da problemática. O autor identifica, ainda, no movimento feminista radical e no marxismo os principais baluartes dos teóricos do gênero, aglutinando-os como "inimigos" a serem combatidos.

Jesús Trillo-Figueroa, advogado do Ilustre Colégio de Madrid e membro da Fundação Canônica del Castillo, ligada à Santa Sé, em livro publicado sobre o assunto, aos afirmar que a "ideologia de gênero" tem exercido "um papel despótico na hegemonia cultural que impera no pensamento e na opinião pública através do politicamente correto", e depois de reconhecer que ela nasceu "na universidade"15 e que foi "propagada por teses doutorais, livros e revistas cientificas", define assim o termo:

\footnotetext{
${ }^{13}$ As reflexões mais recentes de Judith Butler, nome mais conhecido dos "estudos queer", tem contornado, exatamente, a questão de que moralidades e de que valores podem ser construídos para que a vida de todos, a partir das diferenças, possam constituir-se como "vidas dignas de serem vividas", e não como no atual contexto, onde poucas vidas "merecem ser choradas", constituindo-se como "vidas precárias". Sobre isto, ler Butler (2009, 2015, 2015a)

${ }^{14}$ Ao afirmar isso, o autor mostra desconhecimento da perspectiva de gênero tomado como um constructo social, tal como fazem os estudos queer, que afirmam ser o sexo um dado primeiro, bruto, sobre o qual se impõem as representações de cada cultura, o que não faz do sexo algo "insignificante".

${ }^{15} \mathrm{O}$ reconhecimento, por parte dos adversários dos estudos de gênero, de que seu lugar de produção é a Universidade é importante por permitir-nos melhor compreender sua deliberada estratégia de direcionamento das táticas de combate à "ideologia de gênero" exatamente no espaço educacional da escola, lugar onde destina-se, por excelência, as descobertas da universidade e onde o controle dos pais é mais considerável.
} 
Religare, ISSN: 19826605, v.15, n.2, dezembro de 2018, p.505-525.

Entendemos por tal, um conjunto sistemático e coerente de ideais fechado em si mesmo, sobre a base de alguns princípios simples e sem sensíveis, que pretendem dar uma interpretação total da realidade, do sentido da vida, da sociedade e da história. Se trata de um reducionismo, porque explica a totalidade a partir de uma parte: a política e o sexo [...] os ideólogos pensam que a realidade social pode ser compreendida em sua totalidade pelo ser humano; [...] a utopia que preconiza a ideologia de gênero quer estabelecer a sociedade do hedonismo, pois considera que os seres humanos podem alcançar a felicidade na realização de seus próprios desejos sexuais sem limite moral, legal ou inclusive, corporal algum (TRILLO-FIGUEROA, 2009, p.16, tradução nossa, grifo nosso).

Também aqui observamos a deslegitimação dos estudos de gênero por sua suposta permissividade sexual: buscar-se-ia estabelecer uma "sociedade do hedonismo". Para o autor, tais estudos operariam um "reducionismo" ao tentarem compreender o humano apenas a partir do sexo e da política, pondo a felicidade destes apenas nas questões relacionadas à sua dimensão sexual. Ora, segundo os estudos de gênero, o reducionismo é operado justamente pelas representações sociais/ideológicas que, há séculos, leem o destino e a vida dos homens em sociedade, inclusive sua inserção na ordem pública, a partir daquilo que dizem seus corpos. Haver espaços e "coisas" de homem e mulher por serem home e mulher, haver ganhos diferenciados entre os sexos, eis o reducionismo que tais estudos buscam denunciar e desestabelecer.

Negar a felicidade dos humanos aos seus "desejos", como diz o autor, configura-se, ainda como outra dimensão ideológica de nossa cultura que o autor, por representar a manutenção de tal representação, entende como "natural". Os "inimigos" a serem combatidos, posto serem os influenciadores de tais estudos, seriam: as teóricas do feminismo (Simone de Beauvoir, antes de tudo), a psicanálise, o socialismo, o lesbianismo, a Teoria Queer, e as propostas de Educação para a Cidadania.

Nesse sentido, não se pode deixar de traçar, aqui, uma relação entre os atos enunciativos de identificação e de desqualificação do adversário a combater, 
Religare, ISSN: 19826605, v.15, n.2, dezembro de 2018, p.505-525.

forjando, assim, a mobilização de um duplo imaginário: o do adversário a combater, e a do grupo a quem se dirige sua fala. Tomo, aqui, como definição de "imaginário" o que Backzo pontua como o ato de um enunciador, portador de legitimidade frente a um grupo,

delimitar o seu "território" e as suas relações com o meio ambiente e, designadamente, com os "outros"; e corresponde ainda a formar as imagens dos inimigos e dos amigos, rivais e aliados, etc. O imaginário social elaborado e consolidado por uma coletividade é uma das respostas que esta dá aos seus conflitos, divisões e violências reais ou potenciais. Todas as coletividades têm os seus modos de funcionamento específicos a este tipo de representações (BACKZO, 1985, p.309).

A problemática principal, contudo, que incide nas questões escolares, é o que o autor considera como a passagem do "orgulho gay" para o momento do "lobby gay", mais "devastador" para a escol e para a sociedade:

Sem dúvida, estes ativistas se diferenciam dos movimentos de libertação em dois aspectos: o primeiro é que se assentam estritamente nas reivindicações do orgulho gay e lésbico, e não numa intenção de provocar a revolução social e política total; por outro lado, as organizações começaram a tomar a forma de lobby, ou grupos de pressão, bem relacionados com o sistema, para operar uma transformação cultural que normalizasse a homossexualidade nos meios de comunicação, a luta por direitos civis, etc (TRILLO-FIGUEROA, 2009, p. 127).

Por sua vez, o padre brasileiro, consagrado na Comunidade Católica Canção Nova, assim se expressa:

Hoje, quando precisamos nos referir à ideologia de gênero, é mais prático utilizar a expressão agenda de gênero - lembrando-se que o termo agenda significa projeto, planejamento, sequência. [...] A primeira definição do termo ideologia de gênero é, então: movimento que pretende desconstruir a família e os vínculos existentes dentro dela. O segundo passo [...] fortalecer o conceito e a definição do termo gênero em detrimento da definição de sexo (SOLANO, 2016, p. 12, grifo nosso).

Tal como os autores citados anteriormente, o padre brasileiro tem clareza de que as reivindicações ligadas à questões de gênero já tornaram-se, em muitos 
Religare, ISSN: 19826605, v.15, n.2, dezembro de 2018, p.505-525.

lugares, uma "agenda" política. E, no mesmo mecanismo de "simplificação" deturpadora do que dize os estudos, afirma que pretendem "desconstruir a família" (quando na verdade, trata-se de ampliar sua definição), que buscam criar um "sistema educativo e pedagógico" no qual as pessoas não se sintam mais reconhecidas "em sua natureza"16, podendo "descobrir depois se é homem ou mulher", "desconstrução da pessoa" e mesmo a incitação ao "poliamor". Tudo isso, segundo o sacerdote, teria como objetivos: tirar dos pais a responsabilidade sobre o processo educativo, criar políticas públicas de incentivo à "liberalidade" e "condenar de forma taxativa a proposta cristã".

Tendo tomado o pensamento destes três autores como ilustrativos do que pensa o catolicismo acerca do que nomeiam como "ideologia de gênero" e seus "perigos" para a escola, analisaremos, a seguir, algumas tomadas de posição pública, no Brasil, por parte de atores do campo religioso católico acerca da “agenda de gênero" e de como tais tomadas de posição legitima os argumentos apresentados por esses autores, servindo, estes, como verdadeiros "intelectuais orgânicos" a mobilizarem politicamente ideias do campo católico.

\section{A mobilização ideológica contra a "ideologia de gênero"}

O Senado Federal brasileiro aprovou, em 17 de dezembro de 2013, o Projeto de Lei 103/2012, que continha o Plano Nacional de Educação, e que trazia, dentre outros elementos, uma diretriz que orientava as escolas a adotar práticas de superação de "desigualdades educacionais, com ênfase na promoção da igualdade racial, regional, de gênero e orientação sexual". Começaria, ali, uma verdadeira "cruzada" pela rejeição do Plano, tanto a nível nacional como a nível local. Uma vez que o espaço desse artigo não permite uma análise dos debates

\footnotetext{
${ }^{16}$ O apelo à uma "natureza das coisas" é o mecanismo par excellence no qual se assenta a ideologia dominante de uma "verdade sobre os corpos" assentada no "sexo" que os estudos de gênero vieram desconstruir, e que tanto embaraço causam nos defensores da "tradição". Sem essa ideia de "natureza" muitas estruturas de dominação desfazem-se, pois ela ordena os corpos e as mentes, padronizando valores e comportamentos. São "as maneiras de ver, sentir e agir", tal como definidas por Durkheim.
} 
Religare, ISSN: 19826605, v.15, n.2, dezembro de 2018, p.505-525.

que se travaram nos espaços legislativos, centrar-nos-emos na mobilização de autoridades católicas para a orientação de seus fiéis no sentido de “esclarecimento" e de "pressão" sobre os parlamentares.

Já em dezembro de 2013, após a aprovação do Plano no Senado Federal, Dom Antonio Keller, bispo de Frederico Westphalen (RS) publicou nota ${ }^{17}$ dirigida aos fiéis de sua diocese alertando para os "perigos da ideologia de gênero" adentrar os espaços escolares:

Tratando-se de um Projeto de Lei, todas as escolas (mesmo as confessionais) precisariam se adequar, caso fosse sancionado, sob pena de serem acusadas de promover a desigualdade e a discriminação. Por isso, precisamos reagir como cidadãos que vivem a fé cristã e solicitar de nossos representantes que atendam ao pedido do povo brasileiro, profundamente avesso a estas práticas, não aprovando este Projeto de lei da forma como está sendo apresentado.

A nota do bispo fazia-se acompanhar de uma petição on line a que os fiéis deveriam preencher e enviar aos senadores. A petição dizia o seguinte:

\section{Não queremos que a Ideologia de Gênero seja oficializada em nosso país!}

Sr. Senador, venho, por meio deste e-mail exigir a rejeição do substitutivo do PNE, de autoria do senador Vital do Rêgo, e a rejeição da inclusão da igualdade de gênero como diretriz do plano nacional de educação. A imensa maioria dos brasileiros é contra as práticas de sexualização precoce que serão oficializadas em nosso sistema educacional, caso esse substitutivo seja aprovado tal como está. Além disso, a introdução da ideologia de gênero em nossa legislação oficializará a completa subversão da estrutura familiar natural. Por isso insisto no pedido de rejeição ao substitutivo do PNE, bem como na retirada de toda e qualquer noção relativa à igualdade gênero.

Atenciosamente,

[Seu nome]

\footnotetext{
${ }^{17}$ Cuja íntegra pode ser encontrada nesse endereço: http://www.comshalom.org/brasil-ideologia-
} de-genero-incluida-na-educacao/ 
Religare, ISSN: 19826605, v.15, n.2, dezembro de 2018, p.505-525.

Em 03 de abril de 2014, Dom Orani Tempesta, arcebispo do Rio de janeiro, publicou artigo alertando para os "perigos da ideologização das escolas" a partir da introdução de questões próprias à "ideologia de gênero":

É importante saber que a palavra gênero substitui - por uma ardilosa $e$ bem planejada manipulação da linguagem - o termo sexo. Tal substituição não se dá, porém, como um sinônimo, mas, sim, como um vocábulo novo capaz de implantar na mente e nos costumes das pessoas conceitos e práticas inimagináveis. Nesse modelo inovador de sociedade, não existiria mais homem e mulher distintos segundo a natureza, mas, ao contrário, só haveria um ser humano neutro ou indefinido que a sociedade - e não o próprio sujeito faria ser homem ou mulher, segundo as funções que lhe oferecer. Vê-se, portanto, quão arbitrária, antinatural e anticristã é a ideologia de gênero contida no Plano Nacional de Educação (PNE) e que por essa razão merece a sadia reação dos cristãos e de todas as pessoas de boa vontade a fim de pedir que nossos representantes no Congresso Nacional façam, mais uma vez, jus ao encargo que têm de serem nossos representantes e rejeitem, peremptoriamente, a ideologia de gênero em nosso sistema de ensino ${ }^{18}$.

A substituição "ardilosa" do termo "sexo" por "gênero", segundo o arcebispo, que se desprendia da concepção de homem e mulher a partir da natureza dos corpos, tratava-se de um novo termo capaz de "implantar conceitos e práticas inimagináveis", em especial se estivesse presente no cotidiano escolar. Ora, sem dizer, o arcebispo sugere que há uma luta "ideológica" entre duas concepções: a do "gênero", como conjunto de práticas socializadas, em contraposição ao sexo, tido como "natureza". Esse é o campo delimitado como "disputa". No dia 08 de abril de 2014, a Arquidiocese de Brasília, por meio da Comissão de Bioética e Defesa da Vida, fazia chegar ao seus fiéis a seguinte nota:

Manifestamos nosso desacordo com a tentativa, ora em curso, de inclusão da ideologia de gênero no Plano Nacional de Educação, que está sendo discutido e votado na Câmara dos Deputados. Esta tentativa consiste em inserir artigos e cláusulas que, em nome do combate à discriminação, na verdade determinam que $o$

\footnotetext{
${ }^{18}$ A íntegra da nota pode ser encontrada nesse endereço: http://www.comshalom.org/domorani-emite-nota-sobre-ideologia-de-genero-votacao-acontecera-nesta-quarta-feira/.
} 
Religare, ISSN: 19826605, v.15, n.2, dezembro de 2018, p.505-525.

Estado ensine às crianças e adolescentes, nas escolas, como diretriz oficial de governo, que toda e qualquer orientação sexual é igualmente digna e respeitável, desconsiderando e mesmo tornando ilícita qualquer possibilidade de discernir e ensinar os valores verdadeiros da castidade, continência, fidelidade, a abertura natural à vida, a identidade corporal e a responsabilidade com o outro e com a prole na educação de crianças e adolescentes do nosso país.

$[\ldots]$

Por fim, a gravidade da situação se evidencia porque impor a ideologia de gênero na educação significa, em última instância, impedir que a educação brasileira se paute pela verdade, revelada e científica, sobre a pessoa humana e sua sexualidade, que deve representar o objetivo do debate acadêmico realmente livre, porque não há liberdade real senão na verdade.

A leitura do documento deixa entrever a disputa "ideológica" com a "ideologia de gênero": não é possível que o Estado permita, a partir das discussões de gênero, que qualquer forma de orientação sexual seja "igualmente digna e respeitável" (somente uma, portanto, a heterossexual), pois isso não corresponde à "verdade". Contraditoriamente, a Nota defende o "debate acadêmico realmente livre" propondo o interdito às discussões sobre gênero e sobre a s múltiplas identidades, pois tais discussões não corresponde à "liberdade real".

A divulgação da Nota era acompanhada da seguinte mensageminterpelação:

As formas de manifestar a oposição ao projeto são:

a) assinatura em uma plataforma específica no http://www.citizengo.org/pt-pt/5312-ideologia-genero-naeducacao-nao-obrigado

b) ligação gratuita pelo telefone 0800619 619. Tecla "9" pedindo a rejeição à ideologia de gênero em nosso sistema educacional.

Em 29 de junho de 2015, a Conferência Nacional dos Bispos do Brasil (CNBB), através de sua Regional Leste 1 (Rio de Janeiro), publicou uma nota manifestando "profunda preocupação em face das inúmeras tentativas de implantar a ideologia de gênero em nosso país" (n.1), em especial com a possibilidade de tais tentativas fazerem-se presentes dentro do "sistema escolar" 
Religare, ISSN: 19826605, v.15, n.2, dezembro de 2018, p.505-525.

(esse é o momento em que as Planos de Educação começam a ser votados pelo Brasil). Reafirmando que a sexualidade é "uma realidade com a qual já nascemos e para a qual somos chamados a viver" (legitimação por via "natural", portanto"), a Nota afirmava que negar o aspecto biológico e dar ênfase ao aspecto afetivo seria "puro reducionismo", concluindo com um apelo a que os vereadores não permitissem a introdução de tais ideias nas escolas municipais.

Em outubro de 2015 seria a vez de Padre Paulo Ricardo, apresentador de um programa na TV Canção Nova, orientar seus telespectadores, de forma simplória, acerca dos "5 mandamentos da ideologia de gênero"19, que seriam: "não há diferenças entre homem e mulher", "o sexo biológico é modificável", "a família natural é um estereótipo", "dessexualizar a paternidade" e "conquistar a mídia e as escolas". Seu texto concluía-se com uma interpelação "aos pais": "cada um deve escolher se quer deixar para seus filhos um mundo construído sobre a verdade, ou sobre a falsidade de uma ideologia".

\section{Considerações finais}

Ao fim de uma intensa campanha, as menções aos aspectos relativos às questões de gênero e enfrentamento aos preconceitos delas decorrentes saíram derrotadas nas 27 capitais do Brasil, e em 98\% dos municípios. A estratégia desqualificadora que usou como recurso discursivo o combate à "ideologia de gênero" buscou ganhar terreno em face do desconhecimento de amplas parcelas da população, e em especial dos segmentos vinculados a grupos religiosos. É notório destacar que os discurso dos líderes católicos carismáticos tratou as questões de gênero a partir de uma perspectiva reativa, qual seja: a de enquadrar os debates em sua cosmovisão, como se se tratasse de uma "ameaça" ao cânones de sua cosmovisão e de suas "verdades reveladas", traduzindo assim os esforços das teorias sociais em desconstruir as desigualdades construídas

19 Disponível em https://padrepauloricardo.org/blog/os-cinco-mandamentos-da-ideologia-degenero (acesso em 19/09/2017). 
Religare, ISSN: 19826605, v.15, n.2, dezembro de 2018, p.505-525.

socialmente como uma tentativa de subversão de uma suposta natureza essencial da humanidade.

Os discursos reforçam uma perspectiva conservadora da vida social. Ao orientar os fiéis para uma perspectiva de intolerância diante da diversidade, em especial a de gênero e de orientação sexual, os líderes religiosos essencializam um aspecto natural, retirando os componentes históricos que engendram as relações sociais entre indivíduos. Parte significativa do sucesso desse discurso se efetiva na medida em que ele se ergue a partir do reforço da naturalização do status quo e da aceitação das diferenças como bases para desigualdade.

Nesse sentido, é mister reconhecer que, na contemporaneidade, a atuação de lideranças religiosas na esfera pública, utilizando-se dos argumentos da própria modernidade "laicizante", é um dos elementos constituintes mis importantes das dinâmicas da política e com a política, fazendo passar pela religião qualquer tentativa de compreensão do fenômeno político em suas diversas dimensões, em especialmente, como aqui se viu, a dimensão da discussão de políticas públicas.

\section{Referências}

BACKZO, Bronislaw. A imaginação social. In: LEACH, E. et al. AnthroposHomem. Lisboa: Imprensa Nacional/Casa da Moeda, 1985. p.78-100.

BENTO, Berenice. O homem não tece a dor: queixas e perplexidades masculinas. Natal: EdUFRN, 2015.

BURITY, Joanildo. A cena da Religião Pública: contigência, dispersão e dinâmica relacional. Novos Estudos CEBRAP, São Paulo, n.102, São Paulo, p. 89-105, jul2015. Disponível em < https://www.academia.edu/22433913/A_CENA_DA_RELIGI\%C3\%83O_P\%C3 \%9ABLICA>. Acesso em: 01 abr.2018.

BUTLER, Judith. Vida precaria: el poder del duelo y la violencia. Buenos Aires: Paidós, 2009.

Janeiro: Civilização Brasileira, 2015.

- Relatar a si mesmo: crítica da violência ética. Belo Horizonte: Autêntica, 2015a. 
Religare, ISSN: 19826605, v.15, n.2, dezembro de 2018, p.505-525.

BRASIL, Conferência Nacional dos Bispos do. Nota sobre ideologia de gênero. Disponível em: <http://www.comshalom.org/portal/wpcontent/uploads/2015/06/29/portal/Nota-sobre-Ideologia-de-

G\%C3\%AAnero.pdf>. Acesso em: 20 set.2017.

COMISSÂO ARQUIDIOCESANA DE DEFESA DA VIDA. Disponível em: $<$ http://www.comshalom.org/o-perigo-da-ideologia-genero-na-educacao/>.

Acesso em 21 set.2017.

CUNHA, Magali. “'É preciso salvar a família': gênero, religião e política no contexto do neoconservadorismo evangélico nas mídias no Brasil”. In: CUNHA, Magali; LOPES, Paulo Victor Leite; LUI, Janayna. Religião e política: medos sociais, extremismo religioso e as eleições 2014. Rio de Janeiro: Instituto de Estudos da Religião, 2017.

MACHADO, Maria das Dores. Religião e política no Brasil contemporâneo: uma análise dos pentecostais e carismáticos católicos. Religião e Sociedade, Rio de Janeiro, vol.35, p.45-72, dez-2015. Disponível em: < http://www.scielo.br/pdf/rs/v35n2/0100-8587-rs-35-2-00045.pdf >. Acesso em: 30 mar.2018.

Pesquisa com líderes religiosos: questões éticas e metodológicas. Estudos Sociológicos, Araraquara, v.18, n.34, p.39-56, jan-jun. 2013. Disponível em:

https://periodicos.fclar.unesp.br/estudos/article/view/5972/4525>. Acesso em: 27 fev.2018. Religião, cultura e política. Religião e Sociedade, Rio de Janeiro,

n.32, vol. 2, p. 29-56, 2012. Disponível em: <http://www.scielo.br/pdf/rs/v32n2/03.pdf>. Acesso em: 12 fev.2018.

Aborto e ativismo religioso nas eleições de 2010. Revista Brasileira de Ciência Política, n.7, p.25-37, jan.-abr. 2012. Disponível em: <http://www.scielo.br/pdf/rbcpol/n7/a03n7.pdf>. Acesso em: 24 fev.2018.

. Política e religião. Rio de Janeiro: FGV, 2006.

MAINWARING, Scott. Igreja Católica e política no Brasil (1916-1985). São Paulo: Ed. Brasiliense, 1989.

MARIZ, Cecilia. Catolicismo no Brasil contemporâneo: reavivamento e diversidade. In: TEIXEIRA, Faustino. As religiões no Brasil. Petropólis, RJ: Vozes, 2006.

MIRANDA, Julia. Católicos carismáticos e as eleições municipais de 2012. Ciências Sociais Unisinos, São Leopoldo, n. 51, vol. 2, p. 201-211, mai-ago 2015. Disponível

em:<http://revistas.unisinos.br/index.php/ciencias_sociais/article/viewFile/csu.2 015.51.2.10/4794>. Acesso em: 23 fev.2018. . Carisma, sociedade e política: novas linguagens o religioso no político. Rio de Janeiro: Jorge Zahar, 1999.

TRILLO-FIGUEROA, Jesús. La ideología de género. Madrid: Libros Libres, 2009. YANNOULAS, Silvia. "Notas para a integração do enfoque de género na educação profissional" In: Arno Vogel, Trabalhando com a diversidade do 
Religare, ISSN: 19826605, v.15, n.2, dezembro de 2018, p.505-525.

PLANFOR: raça/cor, género e pessoas portadoras de necessidades especiais, São Paulo, Unesp, 2001, pp. 78-91, 2001.

WEBER, Max. Economia e sociedade. 4.ed. Brasília: ed. UnB, 2012.

Recebido em 05-07-2018.

Aprovado em 20-01-2019. 